\title{
Is Facebook Linked to Selfishness? Investigating the Relationships among Social Media Use, Empathy, and Narcissism
}

\author{
Tracy Alloway, Rachel Runac, Mueez Qureshi, George Kemp \\ University of North Florida, Jacksonville, USA \\ Email: t.alloway@unf.edu
}

Received 10 February 2014; revised 16 March 2014; accepted 7 April 2014

Copyright $@ 2014$ by authors and Scientific Research Publishing Inc.

This work is licensed under the Creative Commons Attribution International License (CC BY). http://creativecommons.org/licenses/by/4.0/

(c) (i) Open Access

\begin{abstract}
The rise of social networking sites have led to changes in the nature of our social relationships, as well as how we present and perceive ourselves. The aim of the present study was to investigate the relationship among the following in adults: use of a highly popular social networking site-Facebook, empathy, and narcissism. The findings indicated that some Facebook activities, such as chatting, were linked to aspects of empathic concern, such as higher levels of Perspective Taking in males. The Photo feature in Facebook was also linked to better ability to place themselves in fictional situations. For only the females, viewing videos was associated with the extent to which they could identify with someone's distress. The data also indicated that certain aspects of Facebook use, such as the photo feature, were linked to narcissism. However, the overall pattern of findings suggests that social media is primarily a tool for staying connected, than for self-promotion.
\end{abstract}

\section{Keywords}

Facebook, Empathy, Narcissism, Social Networking Sites

\section{Introduction}

Social networking sites (SNS), like Facebook, give users an opportunity to connect and interact online [1]. Since its creation in 2004, Facebook's growth has been exponential, with around 845 million active users as of February 2012 [2], 95\% of college students use Facebook [3]. With this steady growth of SNS, changes in face-to-face communication have become apparent with people spending more time communicating online than in person [4]. One drawback of this increased SNS use is that individuals may isolate themselves, choosing to talk and form relationships primarily online rather than developing meaningful, face-to-face relationships [5]. Support for this 
possibility comes from a recent report that indicated SNS users are less likely to engage or personally know their neighbors [6].

\subsection{SNS Empathy}

Empathy is characterized as one's ability to feel along with others, to share in their happiness and hardships [7]. In psychology, it has often been defined as a multidimensional construct, comprising both cognitive and behavioral states [8]. As with many desirable prosocial traits, individuals are not born with this innate ability, but learn to become empathic through conditioning methods [9]-[11]. Yet, if one is not exposed to the necessary nurturing to develop empathy into a habit, they may not be able to relate to others, which can impact their social aptness [7].

Current findings on the impact of SNS on empathy are mixed. A positive view is that SNS use can encourage empathy because it allows youth to widen their self-understand and their ability to practice their empathic responses [7] [12]. SNS, like Facebook, provide accessibility to others online, which allows individuals greater opportunities to express their sympathetic feelings that they may ordinarily shy away during more personal interactions [13]. As empathy is developed over time through practice, these behaviors will become more habitual. Wright and Li found that the time spent on online activities was related to prosocial behavior, such as saying nice things, offering help, cheering someone up, and letting someone know one cares about them [14]. Thus, increased exposure to SNS could provide access to situations that foster empathic concern.

An opposing view of the impact of SNS on empathy is that increased use can lead to a desensitization of other's sentiments, resulting in a lack of empathy [4]. Constant SNS use can create a constant bombardment of high-level emotions and negative events in other people's lives that one would not normally be exposed to. In order to compensate, one becomes hardened to emotional experiences, which can affect face-to-face interactions. When Konrath and colleagues examined changes in empathy levels in college students between 1979 and 2009, they found a significant decrease in empathic concern and perspective taking, particularly in the last decade, which coincides with the rise in SNS use. They suggested that the shift in empathy levels could be driven by a more individualistic and self-centered attitude, as indicated by the label of "Generation Me" [15]. Support for this view comes from a survey that found only a small percentage of young adults listed helping others as their primary goal, while the majority indicated that becoming wealthy was the most important goal in their lives [16].

\subsection{Empathy \& Narcissism}

The apparent decrease in empathy [4] coincides with a reported rise in narcissism-30\% in the last 25 years, particularly in college students [17] Ritter et al. directly compared the relationship between narcissism and empathy and found that individuals with Narcissistic Personality Disorder (NPD) had a lower propensity for perspective taking (a construct of empathy), compared to the control group without NPD. The authors argued that a lack of empathy is a key feature of narcissism [18].

\subsection{SNS \& Narcissism}

Narcissistic individuals are characterized by a positive and exaggerated view of themselves, including their physical attractiveness and importance [19] [20]. Although SNS like Facebook can offer a platform to engage in narcissistic behavior, the link is still unclear. Buffardi and Campbell found college students who scored higher on the Narcissistic Personality Inventory listed more Facebook friends [21]. This pattern fits with the reported high rate of social extraversion, with bonds that typically lack warmth or strong emotion, in narcissists [22] [23].

Another feature of narcissistic behavior is the practice of self-regulatory actions aimed at increasing a social perception of a positive self [24], including attention-seeking behavior [25]. However, Bergman et al. found that narcissism was not a strong predictor of either frequency of status updates or time spent on SNS [26]. The authors suggested that SNS use is a means of staying connected, rather than attention-seeking behavior.

\subsection{Present Study}

The aim of the present study was to investigate the relationship among SNS, empathy, and narcissism. We selected Facebook in light of its popularity [27]. We also extended previous research by investigating the links 
among narcissism, empathy, and SNS. The majority of studies to date have focused on narcissism and SNS, or empathy and SNS. However, given narcissism has been defined as a "lack of empathy" [28], it is useful to understand the relationship among these three components. There are key implications for understanding this relationship, as it can provide a useful first step in minimizing the affect of cyberbullying. Coinciding with the surge in social networking, there has been an increase in cyperbullying. In the United States, as well as Canada, Australia, and Europe, the prevalence rate of cyberbullying is between $6 \%$ and $17 \%$ [29]-[33]. Due to the anonymity of SNS, cyberbullies do not have to face the consequences of their actions, and thus may experience less empathy.

We were also interested in sex differences. There are clear patterns of higher narcissism scores for males [34], however current research is mixed regarding sex and empathic levels [35], Thus, all of the following research questions were investigated separately for male and female participants. While the majority of previous research on SNS has targeted college students, the present study included a broad range, from 18 to 50 years, to represent the increased presence of adults using social media [36]. Additionally, narcissism has been shown to decrease as people age [37]. The research questions were:

- Question 1: How do different Facebook activities relate to empathy?

- Question 2: What is the relationship between empathy and narcissism?

- Question 3: Is Facebook usage linked to narcissism?

\section{Method}

\subsection{Participants}

There were 410 volunteers, ranging between 18 and 50 years; $82 \%$ of participants aged 18 to 25 (male: $25 \%$ ). Of the respondents, $73.6 \%$ were White, 9\% were African American, 6.7\% were Hispanic, and 5.2\% were Asian. The majority of participants were single (82\%), $11.1 \%$ were married, with the remainder classified as divorced, widowed, or separated. Most participants were college-educated (92\%); the remaining $8 \%$ had completed high school.

\subsection{Procedure}

Volunteers were recruited over a two-month period. The study was advertised on the university research participation system. The criteria for participation was that they had to be Facebook users with English as their first language, and aged between 18 and 50. The researchers also posted a message on their Facebook wall. Individuals who chose to participate clicked on a link hosted by a third-party website, Qualtrics.

\subsection{Measures}

\subsubsection{Facebook Usage}

Participants indicated the time spent on Facebook (hours per day) and the number of friends. They also indicated whether they were in their current profile picture, how regularly they changed it, and rated their profile picture against the following criteria - physically attractive, cool, glamorous, and fashionable — on a Likert scale (1 to 5, Cronbach's alpha was 0.80 ). The four rating criteria questions were averaged to create a single score.

\subsubsection{Facebook Activities}

A Facebook questionnaire was used [38] and included the frequency of: playing games, sharing links, sending private messages, and posting, viewing, or commenting on photos or videos (Likert Scale: $0=$ Never to $5=$ Very frequently $/ 100 \%$ of the time).

In order to confirm the reliability (internal consistency) of the survey used to measure Facebook activities, a principal-components analysis was conducted on the raw scores for all 16 questions, rotated to final solution with a Varimax rotation. Five factors emerged with eigenvalues in excess of 1.00 , accounting for $66.4 \%$ of the variance (Table 1). The questions that loaded most highly on Factor 1 related to viewing and commenting on photos (FB Photos). The highest loading measures on Factor 2 related to videos and apps (FB Videos Apps). Factor 3 related to the frequency of chatting and sending private messages (FB Chat), while Factor 4 corresponds to commenting on status updates and sharing links (FB Links). Scores were averaged on this basis and 
Table 1. Factor loadings on the principal components analysis (only loadings $>0.45$ are shown).

\begin{tabular}{|c|c|c|c|c|c|}
\hline Items & $\begin{array}{l}\text { Photos } \\
\left(34 \%^{*}\right)\end{array}$ & $\begin{array}{c}\text { Video/Apps } \\
\left(11 \%^{*}\right)\end{array}$ & $\begin{array}{l}\text { Chat } \\
\left(9 \%{ }^{*}\right)\end{array}$ & $\begin{array}{l}\text { Links } \\
\left(7 \%{ }^{*}\right)\end{array}$ & $\begin{array}{l}\text { Games } \\
\left(3.4 \%^{*}\right)\end{array}$ \\
\hline Posting photos of you (in a group, individual, etc.) & 0.838 & & & & \\
\hline Posting photos in general (scenery, pets, kids etc.) & 0.795 & & & & \\
\hline Tagging photos & 0.721 & & & & \\
\hline Commenting (statuses, wall posts, pictures, etc.) & 0.568 & & & & \\
\hline Viewing photos & 0.554 & & & & \\
\hline Tagging videos & & 0.820 & & & \\
\hline Posting videos & & 0.777 & & & \\
\hline Viewing videos & & 0.682 & & & \\
\hline Applications (Running, Wine, Marketplace, etc.) & & 0.618 & & & \\
\hline Chatting on Facebook chat & & & 0.811 & & \\
\hline Sending private messages & & & 0.748 & & \\
\hline Checking to see what someone is up to & 0.500 & & 0.511 & & \\
\hline \multicolumn{6}{|l|}{ Creating or RSVP'ing to events } \\
\hline Sharing links & & & & 0.825 & \\
\hline Posting status updates & 0.497 & & & 0.704 & \\
\hline Playing games (Farmville, Mafia Wars, etc.) & & & & & 0.831 \\
\hline
\end{tabular}

Note: ${ }^{*}$ Proportion of variance.

used for further analyses. The question on how often they played games loaded on a separate factor (Factor 5), and the question on creating and replying to events did not load highly on any factor. Both these items were eliminated from additional analyses.

\subsubsection{Empathy}

We used the Interpersonal Reactivity Index (IRI) [8] [39]. Cognitive empathy is measured by: the Fantasy scale - the tendency to identify with fictional characters and Perspective Taking - the ability to place oneself in another's situation. Emotional empathy is measured by: Empathic Concern - the sympathetic feelings for other's misfortunes and Personal Distress - the anguish felt during other's hardships and troubles. Each of the four subscales is comprised of seven items, which are rated on a five-point scale $(\mathrm{A}=$ does not describe me well to $\mathrm{E}=$ describes me very well). The maximum score for each subscale is 35 , with higher numbers indicating higher levels of empathy.

\subsubsection{Narcissism}

The Narcissistic Personality Inventory-16 [40], a short form of the NPI-40 $(r=0.90)$, reflects the multiple facets of narcissism, such as self-ascribed authority, superiority, entitlement, and self-absorption [41]. NPI scores are inversely related to empathy [42]. The NPI-16 is a forced-choice questionnaire, with higher scores representing greater narcissistic tendencies (narcissism $=1$; non-narcissism $=0$ ).

\section{Results}

Participants used Facebook for an average of two hours per day (range: 30 minutes - 15 hours, Table 2). Facebook use for the day of testing was significantly correlated with time spent the day before $(r=0.73, p<0.001)$. The average number of friends on Facebook was close to 500 for both males and females, with the majority reporting that they were in their current profile picture $(89.5 \%)$.

For Facebook Usage, independent t-test confirmed that females spent more time per day on Facebook and 
Table 2. Descriptive statistics of Facebook questions, empathy, and narcissism, as a function of gender.

\begin{tabular}{|c|c|c|c|c|c|}
\hline & Males & $\mathrm{N}=101$ & Females & $\mathrm{N}=309$ & $F(\text { eta })^{* *}$ \\
\hline Facebook Usage & Mean & SD & Mean & SD & $t$ \\
\hline Time spent per day (hours) & 1.55 & 1.60 & 2.01 & 2.031 & $-2.04^{*}$ \\
\hline Number of friends & 488.91 & 468.51 & 476.33 & 373.29 & $<1$ \\
\hline Frequency of changing profile picture (days) & 87.42 & 114.44 & 63.66 & 90.08 & $2.14^{*}$ \\
\hline Profile picture ratings & 3.43 & 1.18 & 3.80 & 0.91 & $-3.19^{*}$ \\
\hline \multicolumn{6}{|l|}{ Facebook Activities } \\
\hline FB Photos & 2.73 & 0.73 & 3.22 & 0.74 & $33.45^{*}(0.08)$ \\
\hline FB Videos Apps & 1.91 & 0.77 & 1.86 & 0.73 & 0.28 \\
\hline FB Chat & 2.92 & 0.87 & 3.00 & 0.84 & 0.64 \\
\hline FB Sharing links and updates & 2.79 & 1.02 & 2.78 & 0.88 & 0.05 \\
\hline \multicolumn{6}{|l|}{ Empathy (IRI) } \\
\hline Perspective Taking & 25.09 & 4.71 & 25.96 & 5.06 & $<1$ \\
\hline Fantasy Scale & 22.59 & 5.94 & 23.94 & 5.77 & $4.08^{*}(0.01)$ \\
\hline Empathic Concern & 24.43 & 4.84 & 26.67 & 5.16 & $15.19^{*}(0.04)$ \\
\hline Personal Distress & 15.89 & 4.72 & 18.68 & 5.01 & $24.64^{*}(0.06)$ \\
\hline Narcissism (NPI-16) & 0.36 & 0.20 & 0.30 & 0.19 & $2.82^{*}(t$ value $)$ \\
\hline
\end{tabular}

Note: ${ }^{*}=\mathrm{p}<0.05$ between gender. ${ }^{* *}=\mathrm{F}$ value unless otherwise stated.

rated their profile picture as more attractive, cool, fashionable or glamorous, compared to their male peers (Table 2). However, the females changed their profile picture more often than the males. For Facebook Activities, a MANOVA confirmed a significant sex difference (Hotelling's T-test: $F=18.95, p<0.001$ ). Bonferroni adjustment for multiple comparisons indicated that females reported a significantly higher frequency of viewing, posting, and tagging photos compared to their male peers.

- Question 1: Are different Facebook activities related to empathy?

A MANOVA confirmed a sex difference in the empathy scales (Hotelling's T-test: $F=11.89, p<0.001$; Table 2). Bonferroni adjustment for multiple comparisons indicated indicated that females scored significantly higher than males in all empathy subscales, except for Perspective Taking.

Correlation analyses were conducted to investigate the relationship between empathy and engagement with different Facebook activities, as a function of sex (Table 3). Perspective Taking was significantly related to FB Chat for males. The Fantasy Scale was significantly related to FB Photos for both males and females, and for FB Chat and FB Links for males. Empathic Control was not significantly related to any Facebook factor. Personal Distress was negatively associated with FB Chat for males and to FB Videos and Apps for females. For males, this suggests that the frequency of chatting and sending messages was related to how well they could place themselves in another's situation, as well as their ability to identify with fictional characters. However, they were less likely to feel the anguish of another's hardships. For females, viewing and commenting on photos was significantly related to their ability to identify with fictional characters, and viewing videos and apps was associated with the extent to which they could identify with someone's distress.

- Question 2: What is the relationship between empathy and narcissism?

For males, empathy was not significantly related to narcissism (Table 3). However, for females, Personal Distress was significantly linked to narcissism.

- Question 3: Is Facebook usage linked to narcissism?

For both males and females, posting, tagging, and commenting on photos (FB Photo factor) were associated with their self-reported narcissism score (Table 3). For females only, greater frequency of sharing links and 
Table 3. Correlations coefficients for the male participants in the lower half $(\mathrm{n}=101)$; and for the female participants in the upper half $(\mathrm{n}=309)$.

\begin{tabular}{|c|c|c|c|c|c|c|c|c|c|}
\hline & 1 & 2 & 3 & 4 & 5 & 6 & 7 & 8 & 9 \\
\hline 1. FB Photos & 1 & $0.49^{* *}$ & $0.52^{* *}$ & $0.58^{* *}$ & -0.003 & $0.16^{* *}$ & 0.02 & 0.05 & $0.11^{*}$ \\
\hline 2. FB Video Apps & $0.57^{* *}$ & 1 & $0.36^{* *}$ & $0.34^{* *}$ & -0.03 & -0.001 & -0.10 & $0.14^{*}$ & 0.07 \\
\hline 3. FB Chat & $0.58^{* *}$ & $0.33^{* *}$ & 1 & $0.28^{* *}$ & 0.01 & 0.10 & -0.01 & 0.07 & 0.04 \\
\hline 4. FB Links & $0.71^{* *}$ & $0.50^{* *}$ & $0.37^{* *}$ & 1 & 0.06 & 0.10 & 0.04 & -0.03 & $0.15^{* *}$ \\
\hline 5. Perspective Taking (IRI) & 0.11 & 0.001 & $0.31^{* *}$ & 0.10 & 1 & $0.33^{* *}$ & $0.59^{* *}$ & $-0.27^{* *}$ & -0.02 \\
\hline 6. Fantasy Scale (IRI) & $0.26^{* *}$ & 0.14 & $0.28^{* *}$ & $0.28^{* *}$ & $0.42^{* *}$ & 1 & $0.44^{* *}$ & 0.04 & -0.05 \\
\hline 7. Empathic Concern (IRI) & 0.11 & 0.01 & 0.13 & 0.14 & $0.58^{* *}$ & $0.47^{* *}$ & 1 & $-0.14^{*}$ & -0.10 \\
\hline 8. Personal Distress (IRI) & -0.06 & 0.02 & $-0.28^{* *}$ & -0.09 & $-0.34^{* *}$ & 0.04 & -0.05 & 1 & $-0.13^{*}$ \\
\hline 9. Narcissism (NPI-16) & $0.21^{*}$ & 0.15 & 0.17 & 0.09 & -0.12 & 0.11 & -0.08 & -0.11 & 1 \\
\hline
\end{tabular}

Note: ${ }^{* *}=\mathrm{p}<0.01 ;^{*}=\mathrm{p}<0.05$.

posting status updates were also linked with more narcissistic tendencies.

To order to investigate whether Facebook use was linked to narcissism, stepwise regression analyses was conducted for males and females separately (Table 4). Predictor variables were the Facebook usage questions (number of friends, time spent on Facebook per day, frequency of changing profile picture, and profile picture ratings); as well as often they posted status updates and photos of themselves [26]. For males, only their profile picture ratings were a predictor of narcissism. For the females, both their profile picture ratings and their status update frequency predicted their narcissism score.

\section{Discussion}

- Question 1: How do different Facebook activities relate to empathy?

Females scored significantly higher than males in all empathy subscales, except for Perspective Taking. This is consistent with Davis' data [39], though group means are substantially higher in the present study. The pattern between Facebook and empathy also differed as a function of sex. For males, chatting on Facebook was linked to higher scores in Perspective Taking, though there were also less sensitive to another's hardships. It could be that increased social media usage provided opportunities for the males in the present study to practice such prosocial skills [13], but they aren't more likely to feel discomfort at another's distress. In contrast, for females, Personal Distress scores were linked to watching videos on Facebook. For both males and females', certain Facebook activities (chatting and commenting/viewing photos, respectively) were related to their ability to identify with fictional characters.

- Question 2: What is the relationship between empathy and narcissism?

First, it is worth noting that the NPI-16 scores in the present study were similar to previous research [41]. However, empathy levels do not appear to be declining, as IRI scores were considerably higher than those reported by Davis [39]. However, the issue of test wiseness in the participants cannot be ruled out - even though data collection was anonymous, participants may have exaggerated their responses to present themselves more favorably. An alternate explanation could be that the wider age range $(18-50)$ in present study may account for the higher empathy scores, as previous samples were typically in the 18 - 25 range [4].

In the present study, the relationship between empathy and narcissism was not significant for males. For females, only narcissism was related to Personal Distress, a "self-oriented" reaction [8]. A narcissistic person would find it difficult to express emotional empathy because of their preoccupation with themselves and disinterest other's misfortunes.

- Question 3: Is Facebook usage linked to narcissism?

Looking first at Facebook activities, commenting and viewing photos was significantly related to narcissism scores for both males and females. Also, posting status updates and sharing links was associated with narcissism scores for females. As the Facebook News Feed provides notifications for comments on photos, as well as status 
Table 4. Stepwise regression analyses predicting narcissism scores, as a function of gender.

\begin{tabular}{|c|c|c|c|c|}
\hline & $R^{2}$ change & $F$ & $\beta$ & $\mathrm{t}$ \\
\hline \multicolumn{5}{|l|}{ Males } \\
\hline Rating of Profile Picture & 0.11 & $10.06^{*}$ & 0.33 & $2.24^{*}$ \\
\hline \multicolumn{5}{|l|}{ Females } \\
\hline Rating of Profile Picture & 0.10 & $28.24^{*}$ & 0.28 & $4.76^{*}$ \\
\hline Frequency of updating status & 0.03 & 8.73 & 0.18 & $2.95^{*}$ \\
\hline
\end{tabular}

${ }^{*} \mathrm{p}<0.05$.

updates and links shared, the attention received may be a key factor for why these activities are linked to narcissism. Although the present study found that commenting and viewing photos were related to narcissism, we did not investigate the nature of the comments being left by users. If future research can explore potential differences in the type of comments that male and female users receive, it may explain why narcissistic users make a more conscious effort to pursue these activities.

Next, with respect to Facebook usage, profile picture ratings predicted narcissism scores for both males and females. Narcissistic individuals are characterized by a positive and exaggerated view of themselves, especially with characteristics concerning their physical attractiveness. The profile picture is the most physical aspect of a user's online self-presentation. Facebook manages a users' attention directly by reporting changes, and therefore being very effective at increasing the spotlight on the user. Narcissistic individuals therefore may use this tool to direct attention to them.

Additionally, the female participants rated their profile pictures as more physically attractive, fashionable, glamorous, and cool, than the males. This could imply that female narcissistic users are more concerned with, and give greater value, to a profile that maintains a more physically appealing self-presentation. If women receive more compliments on their profile pictures, then updating the profile picture would give them more opportunities to receive positive reinforcement for their online self-presentation. Future research could explore this possibility.

The results showed that the act of uploading more or less photos of oneself on Facebook did not vary among any groups within the present study. This implies that managing the number of photos of oneself on Facebook is not a strategy used by narcissistic individuals.

For females, only posting status updates was a significant predictor of narcissism, which is consistent with previous findings of posting self-promoting information on SNS [21]. It is possible that for females, Facebook offers an avenue for them to present a positive "public" self and bolster self-esteem. However, the time spent on Facebook or the frequency of posting photos of themselves was not predictive of narcissism for either males or females. This pattern mirrors that found by Bergman et al. [26], who suggest that these activities are not attention-seeking, but rather a means of communicating.

To summarize, the present research found that some Facebook activities, such as chatting, was linked to higher levels of Perspective Taking in males. This pattern suggests that Facebook, in facilitating great social connection, may encourage some aspects of empathy in contrast to previous reports [4]. Although the photo feature was linked to narcissism, the general pattern suggests that Facebook is primarily a tool for staying connected, than for self-promotion.

\section{References}

[1] Murray, K.E. and Waller, R. (2007) Social Networking Goes Abroad. International Educator, 16, 56-59.

[2] Protalinski, E. (2012) Facebook Has over 845 Million Users. ZDNet. Retrieved February 4.

[3] Lampe, C., Ellison, N. and Steinfield, C. (2006) A Facebook in the Crowd: Social Searching versus Social Browsing. In: Hinds, P. and Martin, D., Eds. Proceedings of the $200620^{\text {th }}$ Anniversary Conference on Computer Supported Cooperative Work, Alberta, 167-170. http://dx.doi.org/10.1145/1180875.1180901

[4] Konrath, S., O’Brien, E. and Hsing, C. (2010) Changes in Dispositional Empathy in American College Students over Time: A Meta-Analysis. Personality and Social Psychology, 15, 180-198. http://dx.doi.org/10.1145/1180875.1180901 
[5] Putnam, R.D. (2000) Bowling Alone. Simon \& Schuster, New York.

[6] Hampton, K.N., Sessions, L.F., Her, E.J. and Rainie, L. (2009) Social Isolation and New Technology. Pew Internet and American Life Project. http, //wwwpewinternetorg/Reports/2009/18--Social-Isolation-and-New-Technologyaspx

[7] Vallor, S. (2009) Social Networking Technologies and the Virtues. Ethics and Information Technology, 12, $157-170$. http://dx.doi.org/10.1007/s10676-009-9202-1

[8] Davis, M.H. (1983) Measuring Individual Differences in Empathy: Evidence for Multidimensional Approach. Journal of Personality and Social Psychology, 44, 113-126. http://dx.doi.org/10.1037/0022-3514.44.1.113

[9] Feshbach, N.D. (1983) Learning to Care: A Positive Approach to Child Training and Discipline Journal of Clinical Child Psychology, 12, 266-271. http://dx.doi.org/10.1080/15374418309533142

[10] Feshbach, N. and Cohen, S. (1988) Training Affects Comprehension in Young Children: An Experimental Evaluation. Journal of Applied Developmental Psychology, 9, 201-210. http://dx.doi.org/10.1016/0193-3973(88)90023-8

[11] Hatcher, S.L., Nadeau, M.S., Walsh, L.K., Reynolds, M., Galea, J. and Marz, K. (1994) The Teaching of Empathy for High School and College Students: Testing Rogerian methods with the Interpersonal Reactivity Index. Adolescence, 29, 961-974.

[12] Stern, S. (2008) Producing Sites Exploring Identities: Youth Online Authorship. Youth Identity and Digital Media, 95117.

[13] Wandel, T.L. (2009) Online Empathy: Communicating via Facebook to Bereaved College Students. Journal of New Communications Research, 4, 42-53.

[14] Wright, M.F. and Li, Y. (2011) The Associations between Young Adults' Face-To-Face Prosocial Behaviors and Their Online Prosocial Behaviors. Computers in Human Behavior, 27, 1959-1962. http://dx.doi.org/10.1016/j.chb.2011.04.019

[15] Twenge, J.M. (2006) Generation me. Free Press, New York.

[16] Pew Research Center (2007) How Young People View Their Lives Futures and Political: A Portrait of Generation Next. http, //people-pressorg/reports/pdf/300pdf

[17] Twenge, J.M., Konrath, S., Foster, J.D., Campbell, W.K. and Bushman, B.J. (2008) Ego Inflating over Time: A Cross-Temporal Meta-Analysis of the Narcissistic Personality Inventory. Journal of Personality, 76, 875-902. http://dx.doi.org/10.1111/j.1467-6494.2008.00507.x

[18] Ritter, K, Roepke, S., Merkl, A., Heuser, I., Fydrich, T. and Lammers, C.H. (2010) Comorbidity in Patients with Narcissistic Personality Disorder in Comparison to Patients with Borderline Personality Disorder. Psychotherapie, Psychosomatik, Medizinische Psychologie, 60, 14-24. http://dx.doi.org/10.1055/s-0028-1102943

[19] Campbell, W.K., Rudich, E.A. and Sedikides, C. (2002) Narcissism Self-Esteem and the Positivity of Self-Views: Two Portraits of Self-Love. Personality and Social Psychology Bulletin, 28, 358-368. http://dx.doi.org/10.1177/0146167202286007

[20] John, O.P. and Robins, R.W. (1994) Accuracy and Bias in Self-Perception: Individual Differences in Self-Enhancement and the Role of Narcissism Journal of Personality and Social Psychology, 66, 206-219. http://dx.doi.org/10.1037/0022-3514.66.1.206

[21] Buffardi, L.E. and Campbell, W.K. (2008) Narcissism and Social Networking Web Sites. Personality and Social Psychology Bulletin, 34, 1303-1314. http://dx.doi.org/10.1177/0146167208320061

[22] Campbell, W.K. (1999) Narcissism and Romantic Attraction. Journal of Personality and Social Psychology, 77, $1254-$ 1270. http://dx.doi.org/10.1037/0022-3514.77.6.1254

[23] Carroll, L. (1987) A Study of Narcissism Affiliation Intimacy and Power Motives among Students in Business Administration. Psychological Reports, 61, 355-358. http://dx.doi.org/10.2466/pr0.1987.61.2.355

[24] Campbell, W.K., Rudich, E.A. and Sedikides, C. (2002) Narcissism, Self-Esteem, and the Positivity of Self-Views: Two Portraits of Self-Love. Personality and Social Psychology Bulletin, 28, 358-368. http://dx.doi.org/10.1177/0146167202286007

[25] Buss, D.M. and Chiodo, L.M. (1991) Narcissistic Acts in Everyday Life. Journal of Personality, 59, 179-215. http://dx.doi.org/10.1111/j.1467-6494.1991.tb00773.x

[26] Bergman, S.M., Fearrington, M.E., Davenport, S.W. and Bergman, J.Z. (2011) Millennials Narcissism and Social Networking: What Narcissists Do on Social Networking Sites and Why. Personality and Individual Differences, 50, 706-711. http://dx.doi.org/10.1016/j.paid.2010.12.022

[27] Green, E.W. (2005) The Web of Social Networking. US News and World Report, 139, 58.

[28] Ritter, K., Dziobek, I., Preißler, S., Rüter, A., Vater, A., Fydrich, T. and Roepke, S. (2011) Lack of Empathy in Patients with Narcissistic Personality Disorder. Psychiatry Research, 187, 241-247. 
http://dx.doi.org/10.1016/j.psychres.2010.09.013

[29] Campbell, M.A. (2005) Cyber Bullying: An Old Problem in a New Guise? Australian Journal of Guidance and Counseling, 15, 68-76. http://dx.doi.org/10.1375/ajgc.15.1.68

[30] Li, Q. (2006) Cyber Bullying in Schools: A Research of Gender Differences. School Psychology International, 27, 157170. http://dx.doi.org/10.1177/0143034306064547

[31] NCH. (2005) Putting U in the Picture-Mobile Phone Bullying Survey. http://wwwnchorguk/uploads/documents/Mobile bullying \%20reportpdf/

[32] Smith, P.K., Mahdavi, J., Carvalho, M., Fisher, S., Russell, S. and Tippett, N. (2008) Cyberbullying: Its Nature and Impact in Secondary School Pupils. Journal of Child Psychology and Psychiatry, 49, 376-385. http://dx.doi.org/10.1111/j.1469-7610.2007.01846.x

[33] Ybarra, M. and Mitchell, K. (2004) Online Aggressor/Targets Aggressors and Targets: A Comparison of Associated Youth Characteristics. Journal of Child Psychology and Psychiatry, 45, 1308-1316. http://dx.doi.org/10.1111/j.1469-7610.2004.00328.x

[34] Reinhard, D.A., Konrath, S.H., Lopez, W.D. and Cameron, H.G. (2012) Expensive Egos: Narcissistic Males Have Higher Cortisol. PLoS ONE, 7, Article ID: e30858. http://dx.doi.org/10.1371/journal.pone.0030858

[35] Klein, K. and Hodges, S. (2001) Gender Differences, Motivation and Empathic Accuracy: When It Pays to Understand. Personality and Social Psychology Bulletin, 27, 720-730. http://dx.doi.org/10.1177/0146167201276007

[36] Lenhart, A., Purcell, K., Smith, A. and Zickuhr, K. (2010) Social Media and Internet Use among Teens and Young Adults. Pew Research Center.

[37] Foster, J.D., Campbell, W.K. and Twenge, J.M. (2003) Individual Differences in Narcissism: Inflated Self-Views across the Lifespan and around the World. Journal of Research in Personality, 7, 469-486. http://dx.doi.org/10.1016/S0092-6566(03)00026-6

[38] Junco, R. (2011) Too Much Face and not Enough Books: The Relationship between Multiple Indices of Facebook Use and Academic Performance. Computers in Human Behavior, 28, 187-198. http://dx.doi.org/10.1016/j.chb.2011.08.026

[39] Davis, M.H. (1980) A Multidimensional Approach to Individual Differences in Empathy. Catalog of Selected Documents in Psychology, 10, 85.

[40] Mehdizadeh, S. (2010) Self-Presentation 2.0: Narcissism and Self-Esteem on Facebook. Cyberpsychology, Behavior and Social Networking, 13, 357-364. http://dx.doi.org/10.1089/cyber.2009.0257

[41] Ames, D.R., Rose, P. and Anderson, C.P. (2006) The NPI-16 as a Short Measure of Narcissism. Journal of Research in Personality, 40, 440-450. http://dx.doi.org/10.1016/j.jrp.2005.03.002

[42] Watson, P.J., Grisham, S.O., Trotter, M.V. and Biderman, M.D. (1984) Narcissism and Empathy: Validity Evidence for the Narcissistic Personality Inventory. Journal of Personality Assessment, 48, 301-305. http://dx.doi.org/10.1207/s15327752jpa4803 12 